\title{
Quality of life in patients with chronic obstructive pulmonary disease and severe
}

\section{hypoxaemia}

\author{
A A Okubadejo, P W Jones, J A Wedzicha
}

\begin{abstract}
Background-Patients with severe chronic obstructive pulmonary disease (COPD) have impairment in most areas of quality of life, but a relationship between impairment of the partial pressure of oxygen in arterial blood $\left(\mathrm{PaO}_{2}\right)$ and quality of life has not been established. Previous studies used general health measures such as the Sickness Impact Profile (SIP). In this study a disease-specific health measure, the St George's Respiratory Questionnaire (SGRQ), was used to examine the relationship.

Methods - Forty one patients (20 men) of median age 71 years (range 47-85) with COPD were assessed. Forced expiratory volume in one second $\left(\mathrm{FEV}_{1}\right), \mathrm{PaO}_{2}$ and partial pressure of carbon dioxide in the arterial blood $\left(\mathrm{PaCO}_{2}\right)$ were measured, and the patients completed the SGRQ, SIP, and the Hospital Anxiety and Depression Scale (HAD).

Results - The mean (SD) values were: $\mathrm{FEV}_{1}, 0.83(0.29)$ litres; $\mathrm{PaO}_{2}, 7.49$ (1.03) kPa; $\mathrm{PaCO}_{2}, 6.30$ (1.05) kPa; SGRQ total score, $55 \cdot 3$ (18.2); SIP total score $15 \cdot 4$ (9.2); anxiety score, $5 \cdot 7(4 \cdot 3)$; depression score, $5 \cdot 3(3 \cdot 4) . \mathrm{PaO}_{2}$ was significantly correlated with the SGRQ total scores but not with the SIP total score. The SGRQ total score also correlated with anxiety and depression. Multivariate analysis showed that depression score and $\mathrm{PaO}_{2}$ were both significant covariates of the SGRQ total score.
\end{abstract}

Conclusions - These findings suggest that, in patients with severe COPD, quality of life is related to the severity of hypoxaemia, but this relationship is only detectable when using a disease-specific health measure.

(Thorax 1996;51:44-47)

Keywords: chronic obstructive pulmonary disease quality of life, hypoxaemia.

Patients with severe chronic obstructive pulmonary disease (COPD) complicated by chronic hypoxaemia complain of disabling breathlessness and reduced exercise capacity. ${ }^{12}$ In addition, they suffer from depression ${ }^{3}$ and impairment of cognitive function. ${ }^{4}$ Previous studies have shown that measures of lung function such as forced expiratory volume in one second $\left(\mathrm{FEV}_{1}\right)$ do not accurately predict ex- ercise capacity in these patients. ${ }^{56}$ In recent years health-related quality of life questionnaires have been developed to provide standardised measurements of disturbance to daily life and well being due to disease. These have been shown to provide valid measurements of impaired health in COPD. They reflect, and aggregate together, a range of aspects of disease activity and its resulting disability and distress. ${ }^{37-10}$ Unlike the $\mathrm{FEV}_{1}$, these measures correlate quite well with exercise capacity. ${ }^{371112}$

In patients with COPD the severity of chronic hypoxaemia might be expected to influence quality of life. However, previous studies have shown either a weak correlation between quality of life scores and arterial oxygen tension, ${ }^{8}$ or none at all. ${ }^{311}$ These studies all used general health questionnaires such as the Sickness Impact Profile (SIP) ${ }^{13}$ or the Quality of Wellbeing Scale, ${ }^{8}$ rather than measures of health developed specifically for patients with COPD.

In this study a validated disease-specific health measure, the St George's Respiratory Questionnaire (SGRQ), ${ }^{14}$ has been used in addition to the SIP, to test whether the previously reported lack of association between hypoxaemia and disturbance of daily life and wellbeing was due to the choice of measurement instrument.

\section{Methods}

Patients with COPD recruited from outpatient chest clinics in East London were studied. The 41 patients ( 20 men) had a median age of 71 years (range 47-85). Inclusion criteria were a diagnosis of COPD, forced expiratory volume in one second $\left(\mathrm{FEV}_{1}\right)$ of less than 1.5 litres, and a clinically stable condition for at least two weeks. Exclusion criteria were the presence of other major chronic illness and inability to read. None of the patients was using long term oxygen therapy at the time of this study; patients who fitted the criteria for long term domiciliary oxygen therapy were subsequently commenced on this treatment.

Each patient was asked to complete three questionnaires: the SIP, SGRQ, and Hospital Anxiety and Depression scale (HAD) ${ }^{14}$ All questionnaires were self-completed with supervision. The same person supervised administration of the questionnaires in all cases. Non-directive guidance was given on the few occasions when patients had queries about how to respond to the questionnaire. 
The SIP has 136 response items which produce a range of summary component scores, including physical, psychosocial and an overall total score. Each of these scores ranges from 0 to $100 \%$, a score of $0 \%$ indicating no disability. In a previous study almost all healthy control subjects matched for age, sex, and education with a group of patients with COPD had SIP summary scores of less than $10 \% .^{11}$

The SGRQ has 76 items which are weighted to produce three component scores (symptoms, activity, and impact) and a total score. Each of these scores ranges from 0 to 100 , a score of 100 indicating maximum disability.

The HAD is a 14 item instrument which produces separate scores for anxiety and depression ranging from 0 to 21 ; a score of over 10 is judged to be a predictor of a clinical diagnosis of anxiety or depression.

The three questionnaires were completed at one sitting in a randomised order. The patients also underwent spirometric tests and blood gas analysis at rest using arterialised earlobe capillary samples. ${ }^{15}$ The whole assessment was repeated after an interval of two to three weeks, each patient using the same order of questionnaires as had been used at the first assessment.

The study was approved by the ethics committee of the Royal Brompton National Heart and Lung Hospitals, and all patients gave written informed consent to participation in the study.

\section{STATISTICAL ANALYSIS}

The distribution of all variables approximated to normal so parametric tests were used throughout. Significance was accepted at the $\mathrm{p}<0.05$ level.

\section{Results}

Physiological data for the 41 patients from arterial blood gas analysis and spirometric tests

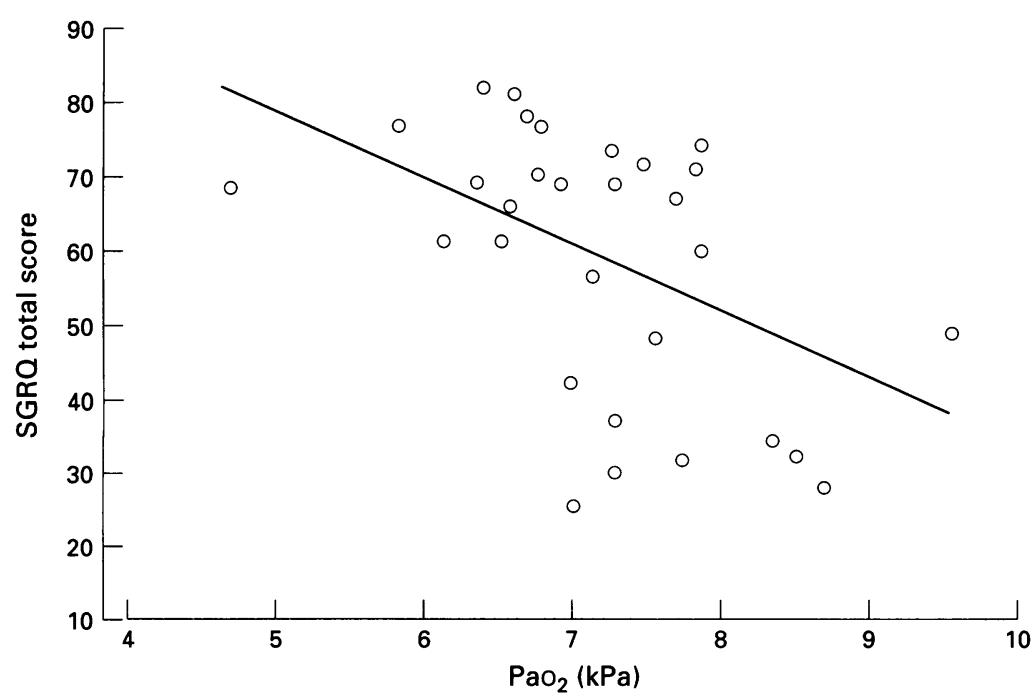

Relationship between quality of life (SGRQ total score) and degree of arterial $\mathrm{PO}_{2}$ hypoxaemia $(n=41, r=0 \cdot 41, p<0 \cdot 01)$.
Table 1 Mean (SD) physiological variables of study patients $(n=41)$

\begin{tabular}{lcc}
\hline Variable & Assessment 1 & Assessment 2 \\
\hline FEV $_{1}(1)$ & $0.83(0.29)$ & $0.81(0.29)$ \\
FEV $_{1}(\%$ pred) & $41.6(16.7)$ & $40.6(15 \cdot 4)$ \\
FVC (1) & $1.85(0.69)$ & $1.91(0.70)$ \\
$\mathrm{FEV}_{1} / \mathrm{FVC}(\%)$ & $46.8(13.7)$ & $47.6(17.2)$ \\
$\mathrm{PaO}_{2}(\mathrm{kPa})$ & $7.49(1.03)$ & $7.45(0.76)$ \\
$\mathrm{PaCO}_{2}(\mathrm{kPa})$ & $6.30(1.05)$ & $6.19(0.85)$ \\
$\mathrm{SaO}_{2}(\%)$ & $86.6(7.0)$ & $87.9(3.6)$ \\
\hline
\end{tabular}

$\mathrm{FEV}_{1}=$ forced expiratory volume in one second; $\mathrm{FVC}=$ forced vital capacity; $\mathrm{PaO}_{2}, \mathrm{PacO}_{2}=$ partial pressure of oxygen and vital capacity; $\mathrm{PaO}_{2}, \mathrm{PaCO}_{2}=$ partial pressure of oxygen and
carbon dioxide in arterial blood; $\mathrm{SaO}_{2}=$ arterial oxygen saturation.

Table 2 Mean (SD) quality of life scores for study patients $(n=41)$

\begin{tabular}{lll}
\hline Health measure & Assessment 1 & Assessment 2 \\
\hline SGRQ & & \\
Symptoms & $64 \cdot 0(21 \cdot 9)$ & $65 \cdot 8(23 \cdot 7)$ \\
Activity & $65 \cdot 2(19 \cdot 8)$ & $62 \cdot 8(18 \cdot 5)$ \\
Impacts & $46 \cdot 5(23 \cdot 5)$ & $45 \cdot 1(22 \cdot 2)$ \\
Total & $55 \cdot 3(18 \cdot 2)$ & $54 \cdot 0(16 \cdot 0)$ \\
SIP & & \\
Physical & $15 \cdot 4(11 \cdot 3)$ & $17 \cdot 7(12 \cdot 0)$ \\
Psychosocial & $13 \cdot 0(10 \cdot 6)$ & $13 \cdot 5(9 \cdot 7)$ \\
Total & $15 \cdot 4(9 \cdot 2)$ & $16 \cdot 7(8 \cdot 6)$ \\
& & \\
HAD & & $5 \cdot 3(3 \cdot 5)$ \\
Anxiety & $5 \cdot 7(4 \cdot 3)$ & $5 \cdot 5(3 \cdot 2)$ \\
Depression & $5 \cdot 3(3 \cdot 4)$ & 5 \\
\hline
\end{tabular}

SGRQ $=$ St George's Respiratory Questionnaire; SIP = Sickness Impact Profile; HAD = Hospital Anxiety and Depression scale.

on the two occasions are shown in table 1 . All patients had evidence of severe chronic airways obstruction with mean $\mathrm{FEV}_{1}$ of $41.6 \%$ predicted. The mean (SD) scores from the questionnaires on the two occasions are shown in table 2. Paired $t$ tests did not demonstrate any significant differences between visits for questionnaire scores, $\mathrm{PaO}_{2}, \mathrm{PaCO}_{2}$, or $\mathrm{FEV}_{1}$. There were significant correlations between $\mathrm{PaO}_{2}$ and $\mathrm{FEV}_{1}(r=0.38, \mathrm{p}=0.01), \mathrm{PaO}_{2}$ and $\mathrm{PaCO}_{2}(r=0.38, \mathrm{p}=0.01)$, and between $\mathrm{FEV}_{1}$ and $\mathrm{PaCO}_{2}(r=0.36, \mathrm{p}=0.02)$.

There was a linear relationship between $\mathrm{PaO}_{2}$ and SGRQ total scores at the first assessment $(r=0.41, \mathrm{p}<0.01)$ as shown in the figure. This relationship was confirmed at the second assessment $(r=0.57, \mathrm{p}<0.001)$. Analysis of covariance showed no significant difference in the regression slopes on the two occasions. There was no significant correlation between $\mathrm{FEV}_{1}$ and SGRQ total score on either occasion. An association of marginal significance was found between $\mathrm{PaCO}_{2}$ and SGRQ total score on both assessments (visit $1, r=0.32, \mathrm{p}<0.05$; visit 2 , $r=0.31$, NS). Correlations between the scores for the component scores of the SGRQ and physiological variables at the first assessment are shown in table 3. The SGRQ symptoms and impacts scores were correlated with level of hypoxaemia, but the activity score was not. Age was not significantly correlated with any SGRQ score $(r \leqslant 0 \cdot 1 ;$ NS).

There were no significant correlations between SIP scores and $\mathrm{FEV}_{1}, \mathrm{PaO}_{2}$, or $\mathrm{PaCO}_{2}$ (table 3). The SGRQ total scores and the SIP total scores were significantly correlated with each other $(r=0.65, \mathrm{p}<0.001)$. 
Table 3 Pearson correlation coefficients between quality of life measures and physiological variables $(n=41)$

\begin{tabular}{llll}
\hline & $\mathrm{FEV}$ & $\mathrm{PaO}_{2}$ & $\mathrm{PaCO}_{2}$ \\
\hline SGRQ & & & \\
Symptoms & 0.03 & $0.34^{*}$ & 0.10 \\
Activity & $0.34^{*}$ & 0.27 & $0.40^{*}$ \\
Impacts & 0.27 & $0.37^{*}$ & 0.24 \\
Total & 0.30 & $0.41^{* *}$ & $0.32^{*}$ \\
SIP & & & \\
$\quad$ Physical & 0.10 & 0.20 & 0.07 \\
Pyychosocial & 0.02 & 0.29 & 0.02 \\
$\quad$ Total & 0.14 & 0.28 & 0.13 \\
HAD & & & \\
Anxiety & 0.14 & $0.36^{*}$ & $0.37^{*}$ \\
Depression & 0.26 & 0.17 & 0.18 \\
\hline
\end{tabular}

$\mathrm{FEV}_{1}=$ forced expiratory volume in one second; $\mathrm{PaO}, \mathrm{Paco}_{2}=$ partial pressure of oxygen and carbon dioxide in arterial blood; $\mathrm{SGRQ}=\mathrm{St}$ George's Respiratory Questionnaire; SIP = Sickness Impact Profile; $\mathrm{HAD}=$ Hospital Anxiety and Depression scale. Impact Profile; HAD of the general measures. All of the items in such questionnaires are relevant to the condition under study. Those included in the SGRQ were selected because they were relevant to the daily lives and well being of the patients, not because of a demonstrated relationship to a physiological variable. In view of this, we conclude that the correlation between hypoxaemia and SGRQ score was not due to an inbuilt bias in the questionnaire that would unduly have favoured a correlation with hypoxaemia. The detection of a correlation with this questionnaire was presumably due to the high content of items relevant to COPD. The correlation between $\mathrm{PaO}_{2}$ and quality of life was found on two separate occasions which makes it unlikely that this was a chance observation.

No significant correlations were found between $\mathrm{FEV}_{1}$ and any quality of life score. Previous studies have also shown such relationships to be weak. ${ }^{8911}$ In addition, there were no patients with an $\mathrm{FEV}_{1}$ value of more than 1.5 litres in the current study so the range of measurements was small, making the detection of a weak correlation more difficult. Our finding of an association between quality of life and anxiety and depression confirms findings from other studies. ${ }^{371116}$ In general, anxiety and depression have been found to be better predictors of quality of life scores than physiological parameters. In this study, multivariate analysis showed that the effect of $\mathrm{PaO}_{2}$ on quality of life was independent of the effect of mood state.

Quality of life questionnaires provide a standardised method of measuring the impact of disease on the health and well being of patients. They attempt a comprehensive coverage but, for reasons of length and practicality, they cannot address all of the possible disturbances that patients may suffer. Furthermore, they have been developed and validated in populations of patients and thus address areas of commonality between patients with the disease in question and do not provide a description of the precise manner in which each individual's life is disturbed. A distinction should therefore be drawn between the quality of life of an individual patient with COPD and the standardised estimate of their impaired health provided by a quality of life questionnaire. It is perhaps unfortunate that the term "quality of life" has been attached to this type of questionnaire. There are many influences upon the quality of life of an individual with COPD. The conclusion to be drawn from this study is that the level of hypoxaemia is one potentially influential factor and, furthermore, one that appears to be independent of the degree of airways obstruction as measured by the $\mathrm{FEV}_{1}$.

We would like to thank Dr J Moore-Gillon, Dr A C Davison, and $\operatorname{DrCM}$ Roberts for allowing us to study their patients.

1 Burrows B, Niden AH, Barclay WR, Kasik JE. Chronic obstructive lung disease. 1. Clinical and physiologic findings in 175 patients and their relationship to age and sex. Am Rev Respir Dis 1965;91:521-39.

2 Jones NL, Jones G, Edwards RHT. Exercise tolerance in chronic airways obstruction. Am Rev Respir Dis 1971;103 477-91 normal range until the $\mathrm{FEV}_{1}$ falls below $50 \%$ of the predicted normal. ${ }^{10}$

Disease-specific questionnaires were developed because of the potential insensitivity 
3 McSweeney AJ, Grant I, Heaton RK, Adams KM, Timms RM. Life quality of patients with chronic obstructive pulmonary disease. Arch Intern Med 1982;142:473-8.

4 Grant I, Heaton RK, McSweeney AJ, Adams KM, Timms RM. Neuropsychologic findings in hypoxemic chronic obstructive pulmonary disease. Arch Intern Med 1982;142: 1470-6.

5 McGavin CR, Gupta SP, McHardy GJR. Twelve minute walking test for assessing disability in chronic bronchitis. BMF 1976;1:822-3.

6 Killian KJ, LeBlanc P, Martin DH, Summers E, Jones NL, Campbell EJM. Exercise capacity and ventilatory, circulatory, and symptom limitation in patients with circulatory, and symptom limitation in patients with
chronic airflow limitation. Am Rev Respir Dis 1992;146: chronic

7 Jones PW, Baveystock CM, Littlejohns P. Relationships between general health measured with the Sickness Impact Profile and respiratory symptoms, physiological measures, and mood in patients with chronic airflow limitation. $A m$ Rev Respir Dis 1989;140:1538-43.

8 Kaplan RM, Atkins CJ, Timms R. Validity of a quality of well-being scale as an outcome measure in chronic obstructive pulmonary disease. 7 Chronic Dis 1984;37: 85-95.
9 Jones PW, Quirk FH, Baveystock CM, Littlejohns P. A selfcomplete measure of health status for chronic airflow limitation:the St George's Respiratory Questionnaire. $A m$ Rev Respir Dis 1992;145:1321-7.

10 Jones PW. Quality of life measurement for patients with diseases of the airways. Thorax 1991;46:676-82.

11 Prigatano GP, Wright EC, Levin D. Quality of life and its predictors in patients with mild hypoxemia and chronic obstructive pulmonary disease. Arch Intern Med 1984;144: 1613-9.

12 Guyatt GH, Berman LB, Townsend M, Pugsley SO, Chambers LW. A measure of quality of life for clinical trials in chronic lung disease. Thorax 1987;42:773-8.

13 Bergner M, Bobbitt RA, Carter WB, Gilson BS. The Sickness Impact Profile: development and final revision of a hess Impact Profile: development and final revision

14 Zigmund AS, Snaith RP. The Hospital Anxiety and Depression Scale. Acta Psychiatr Scand 1983;67:361-70

15 Pitkin AD, Roberts CM, Wedzicha J A. Arterialised earlobe blood gas analysis: an underused technique. Thorax 1994; 49:364-6.

16 Morgan AD, Peck DF, Buchanan DR, McHardy GJR. Effects of attitudes and beliefs on exercise tolerance in chronic bronchitis. BMF 1983;286:171-3. 